Received Date : 15-Nov-2015

Revised Date : 08-Feb-2016

Accepted Date : 13-Feb-2016

Article type : Original Research

\title{
Retrospective success and survival rates of dental implants placed after a ridge
} preservation procedure

Authors: Peter Apostolopoulos, Ivan Darby

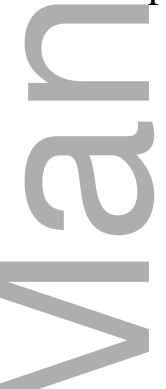

Key Words: success, survival, dental implants, ridge preservation

\section{Contact:}

Professor Ivan Darby,

Periodontics,

$$
\text { - }
$$

Melbourne Dental School,

720 Swanston Street,

Carlton, VIC, 3053,

Australia.

This is the author manuscript accepted for publication and has undergone full peer review but has not been through the copyediting, typesetting, pagination and proofreading process, which may lead to differences between this version and the Version of Record. Please cite this article as doi: $10.1111 / \operatorname{clr} .12820$

This article is protected by copyright. All rights reserved 
Phone (+613) 93411471

Email idarby@unimelb.edu.au

\begin{abstract}
Aim: Ridge preservation is any procedure that takes place at the time of, or shortly after an extraction, to minimise resorption of the ridge and maximise bone formation within the socket. The aim of this project is to investigate the outcome of implant treatment following ridge preservation and compare it to an ungrafted implant control group.

Methods and Materials: Following ethics approval, an electronic and manual search of patient records was conducted and appropriate cases of implant placement following a ridge preservation procedure were identified. Forty two patients with 51 implants at ridge preserved sites were examined by one author (PA) with the following parameters assessed at each implant: pocket probing depth, bleeding on probing, presence/absence of plaque, and radiographic bone loss. Clinical and radiographic findings were compared to an ungrafted implant control group and analysed by years in function.
\end{abstract}

Results: There was a 100\% survival rate of implants in ridge preserved sites. In the majority of cases, ridge preservation was performed in the anterior maxilla with a flap raised and the use of deproteinised bovine bone mineral and collagen membrane materials. The mean time in function was $31( \pm 24)$ months with a range of 2-102 months. Differences in the mean PPD, BOP, plaque index and radiographic bone loss were not statistically significant between implants at ridge preserved or ungrafted sites. The overall success rate was around $58 \%$ for ungrafted implants and around 51\% for implants in ridge preserved sites. However this difference was not statistically significant.

Conclusion: In this retrospective study, implant placement at ridge preserved sites was a predictable procedure that led to very high survival rates and similar success rates to implant placement at ungrafted sites.

\title{
INTRODUCTION
}

When the decision is made to remove a tooth and replace it with an implant, a delay may be often encountered between tooth removal and implant placement. Timing is crucial as a loss 
in the three-dimensional bone volume at the site will occur upon tooth removal, with external resorption of the original socket walls and a varying degree of bone fill within the socket (Hämmerle et al. 2004). Increased delays after tooth removal also result in defect morphologies that represent less favourable situations for implant placement with simultaneous bony regeneration (Zitzmann et al. 1999). The presence of a sufficient volume of healthy bone at the recipient site is one of the most important prerequisites for achieving and maintaining successful osseointegration, as well as peri-implant hard and soft tissues in the long-term. Additionally, implants with missing or thin facial bone may develop soft tissue complications and, therefore, compromised aesthetic outcomes (Chen \& Buser 2009).

Augmentation is very often needed to overcome the changes due to modelling of the alveolar ridge following extraction (Bazrafshan \& Darby 2014). This can be either staged or simultaneous. Staged procedures of augmenting the alveolar process are usually indicated in the presence of advanced bone resorption where there is insufficient bone for implant placement. Simultaneous augmentation occurs at the time of implant placement, which often occurs a few weeks post-extraction. During this period the alveolar ridge loses width and height (Farmer \& Darby 2014). Augmentation is often needed to insert implants of adequate dimensions or to create suitable conditions for an aesthetic and functional implant-supported prosthesis. In situations where insufficient bone is available for implant therapy, bone augmentation techniques are routinely considered. Immediate placement of an implant into the extraction socket, with or without grafting, will not stop modelling of the ridge and loss of the buccal plate (Araujo \& Lindhe 2005, Chen et al. 2009).

Ridge preservation is any procedure that takes place at the time of, or shortly following an extraction, to minimise resorption of the ridge and maximise bone formation within the socket (Darby et al. 2008). Preserving the existing ridge dimensions is especially advantageous for avoiding or minimising the volume of additional ridge augmentation prior to subsequent implant therapy, and is particularly valuable in situations where implant placement needs to be significantly delayed for any reason.

Many techniques have been developed for ridge preservation, generally using a bone graft to fill the socket with a membrane on top to prevent soft tissue ingrowth. A variety of graft materials, such as autogenous bone, allografts, xenografts, and alloplastic materials have been reported in the literature, while most techniques attempt to cover the graft material by using a coronally repositioned flap, a sub-epithelial connective tissue graft, or a collagen wound 
dressing/plug. The most commonly employed ridge preservation technique used a graft placed in the extraction socket, covered by a membrane, followed by flap advancement to achieve complete or partial primary closure (Darby et al. 2009). Data in the literature has demonstrated that, although neither autogenous bone or biomaterials failed to prevent the normal ridge resorption processes that occur during healing following tooth extraction (Araujo \& Lindhe 2011, Araujo et al. 2015), ridge preservation maintained the vast majority of the original horizontal and vertical dimensions compared to ungrafted sites, allowing implant placement without additional grafting at the ridge preserved sites (Cardaropoli et al. 2012). Although ridge preservation is generally successful in reducing the horizontal and vertical bony loss to some degree, there is no evidence that one ridge preservation material or technique is more effective than any other (Darby et al. 2009, Vignoletti et al. 2012).

Many studies have reported on the dimensional changes following ridge preservation; however a more valuable outcome is the ability to place an appropriate implant in the desired restorative position for long-term function. The survival rates of implants placed in ungrafted sites is very high, frequently reported in the range of 97-100\% (Albrektsson et al. 1986, Buser et al. 1997; Lindquist et al. 1997; Leonhardt et al. 2002, Bergenblock et al. 2012). Implants placed in ridge preserved sites have also reported high survival rates in the range of $93-100 \%$, but over much shorter observation periods limited to 12 months (Norton and Wilson 2002, Patel et al.2013). Implant success rates are dependent on the criteria that define their success. Two studies have reported on implant success following ridge preservation in humans, applying success criteria defined by Albrektsson et al. (1986). In sockets grafted with bioactive glass, Norton \& Wilson (2002) showed a cumulative implant success rate of 90\% at one year. Patel et al. (2013) demonstrated similar results at sites ridge preserved with either an alloplast (Straumann Bone Ceramic ${ }^{\circledR}$ ) or a xenograft (BioOss $\left.{ }^{\circledR}\right)$, reporting implant success rates of $84.6 \%$ and $83.3 \%$ respectively. Although these survival and success rates are relatively high, there is little data on the success rates of implants placed after ridge preservation.

Therefore, the present study investigated the survival and success of implant treatment following ridge preservation at the Royal Dental Hospital of Melbourne (RDHM) and compared it to an ungrafted implant control group.

\section{METHODS AND MATERIALS}


Ethics Approval: Ethics approval was obtained from the University of Melbourne, Health Sciences Human Ethics Sub-Committee (Ethics ID 1339456) and Dental Health Services Victoria, Human Research Ethics Committee (Ethics ID 278).

Subject Selection and Criteria: All patients treated with dental implants in RDHM over the period 2002-2012 were identified. A manual audit of these patients' dental records was conducted to identify implant placement following a ridge preservation procedure. Letters were sent to all of these patients to attend for a complementary dental appointment. The control group of implants placed in ungrafted sites was the same as in the study by Bazrafshan \& Darby (2014).

Clinical and Radiographic Examination: All examinations were conducted by the same clinician (PA), who had been previously calibrated for periodontal (peri-implant) probing technique. During each examination, the following clinical parameters were recorded for all implants:

i) pocket probing depth (PPD), the distance in millimetres between the free gingival margin and the base of the peri-implant pocket;

ii) bleeding on probing (BOP), the presence or absence of bleeding up to 30 seconds after probing;

iii) plaque index, the presence or absence of plaque detected by the periodontal probe.

All the above measurements were performed at six sites (disto-buccal, mid-buccal, mesiobuccal, disto-lingual, mid-lingual, mesio-lingual) of each implant using a Williams periodontal probe (Hu-Friedy, Chicago IL, USA), with all measurements rounded up to the nearest millimetre.

A periapical radiograph of each implant was taken to measure radiographic bone levels, using a long-cone paralleling technique with a loop film holder (Rinn, Dentsply Australia Pty Ltd) and plain film (E speed, Eastman Kodak, Rochester NY, USA). The distance in millimetres between the implant-abutment junction and the first clear bone-to-implant contact on both mesial and distal surfaces was recorded (Benic et al. 2009). Where possible, this periapical radiograph was compared to a baseline periapical radiograph (taken straight after insertion of the implant prosthesis) to determine the amount of mesial and distal radiographic bone loss. 
The following additional data were also recorded: age, gender, smoking status (current, past or non smoker), systemic health (including diabetic status), implant details (system, connection type, diameter, length, surface), implant location (by FDI tooth number and anterior/posterior, maxillary/mandibular), tooth extraction details (date, reason), ridge preservation details (date - at time of tooth extraction or not, graft material, membrane use), clinician, implant prosthesis details (restoration date, prosthesis type, time in function) and compliance with an implant maintenance program.

Oral hygiene instruction and supportive periodontal and peri-implant therapy was provided after clinical examination for each patient, with additional appointments for further treatment scheduled where indicated.

Statistical Analysis: Survival was defined as the presence of a dental implant in the jaw. Success was defined using the criteria from Karoussis et al. (2004):

1. Absence of mobility.

2. Absence of persistent subjective complaints (pain, foreign body sensation, dysaesthesia).

3. No PPD $>5 \mathrm{~mm}$.

4. No PPD $=5 \mathrm{~mm}$ and $\mathrm{BOP}$.

5. Absence of continuous radiolucency around implant.

6. After the first year of service, annual vertical bone loss did not exceed $0.2 \mathrm{~mm}$.

Therefore, an unsuccessful implant was one that did not fulfil any of the following clinical or radiographic criteria: $\mathrm{PPD}>5 \mathrm{~mm}$, or PPD $=5 \mathrm{~mm}$ with $\mathrm{BOP}$ (even at one implant site), or mesial or distal annual bone loss $>0.2 \mathrm{~mm}$ after the first year of service (however, a periapical radiograph after one year of service was rarely available).

All statistical data was de-identified and input into a Microsoft Excel spreadsheet (Microsoft Corp, Redmond WA, USA). All statistical analysis was performed using Minitab software (Minitab Inc, State College PA, USA). Statistical analysis included descriptive statistics for all clinical and radiographic parameters assessed for each implant. Clinical and radiographic parameters for test (ridge preserved implants) versus control (ungrafted implants) were compared using student two-sample t-tests and Mann Whitney test for the categorical data. The correlations between these parameters and other variables (age, gender, implant details) were also compared. 


\section{RESULTS}

Of the 400 patients initially identified as potential ridge preservation cases, a manual document audit of these clinical records left 70 patients who met the inclusion criteria of having an implant placed following a ridge preservation procedure, with 42 of these patients attending for clinical examination. The sample consisted of 16 males and 26 females, with a mean age of $53( \pm 16)$ years, ranging from 24 to 79 years (Table 1). Eight patients reported being current smokers and a further eleven smoked prior to implant surgery; however, due to the low numbers, comparisons between smokers and non-smokers were not performed. Four patients were type 2 diabetic at the time of implant surgery, while no other relevant systemic diseases were reported. A review of the patients' periodontal charts prior to implant placement showed that three of them had been diagnosed and treated for periodontal disease. Fifty one dental implants were clinically and radiographically examined by one of the authors (PA). The mean follow-up period after implant placement was $36.5( \pm 25.4)$ months, ranging from 6 to 108 months. The mean time in function was $31.3( \pm 24.6)$ months, ranging from 2 to 102 months. None of the implants were associated with pain, suppuration, foreign body sensation, mobility, or infection at the time of examination.

Forty two implants were placed without grafting in the ungrafted control group, with a mean time in function of $34.8( \pm 24.4)$ months, ranging from 20 to 88 months. Twenty seven implants were placed following a simultaneous ridge preservation procedure at the time of tooth extraction, and twenty four placed following a staged ridge preservation procedure ranging from four to eight weeks (mean of six weeks) after tooth extraction (Table 2). There was a requirement for a mucoperiosteal flap to be raised in fifteen simultaneous and twenty two staged ridge preservation procedures respectively (Table 2). Ridge preservation had been performed following tooth extraction for a number of reasons, including vertical root fractures, trauma-related fractures, failed RCT, unrestorable teeth, periodontitis, internal resorption or other/unstated reasons (Table 4). Ridge preservation mainly involved grafting with DBBM in either particulate form (Bio-Oss, Geistlich, Wolhusen, Switzerland) or within a collagen block (Bio-Oss Collagen, Geistlich, Wolhusen, Switzerland), with the vast majority covered with a bioresorbable collagen membrane (Bio-Gide, Geistlich, Wolhusen, Switzerland) (Table 3).

Four dental implant systems were identified: Straumann (Straumann AG, Basel, Switzerland), AstraTech (Dentsply Implants, Mölndal, Sweden), Biomet 3i (Palm Beach 
Gardens, Florida, USA) and Nobel Biocare (Kloten, Switzerland). The proportions of these implants identified by manufacturer were $39 \%, 35 \%, 14 \%$ and $12 \%$ respectively, with the vast majority of implants configured with an internal connection to the restorative abutment. Seventy eight per cent of the implants located in the anterior maxilla were placed after ridge preservation, with $41 \%$ from a simultaneous and $37 \%$ from a staged approach respectively. Seventy one per cent of all implants were between $8 \mathrm{~mm}$ and $12 \mathrm{~mm}$ in length, with $29 \%$ and $30 \%$ of these placed after simultaneous and staged ridge preservation respectively. Sixty seven percent of all implants were between $3.75 \mathrm{~mm}$ and $4.4 \mathrm{~mm}$ in diameter, with $34 \%$ and $29 \%$ of these placed after simultaneous and staged ridge preservation respectively (Table 4).

Ninety two per cent of implants in ridge preserved sites and $88 \%$ of implants in ungrafted sites had at least one site with BOP. Sixteen per cent and 5\% of implants respectively had at least one site of PPD greater than 5mm. Twenty five per cent of implants in ridge preserved sites and $10 \%$ of ungrafted sites had at least one site of PPD greater than $5 \mathrm{~mm}$ and BOP, which was statistically significant $(\mathrm{p}=0.047)$. Twenty four per cent of implants in ridge preserved sites and $33 \%$ of ungrafted sites had annual bone loss greater than $0.2 \mathrm{~mm}$ after the first year of placement (Table 5). The mean PPD, RBL and percentage of sites with plaque and BOP after 2-102 months in function (presented as years in function) for implants in ridge preserved versus ungrafted sites are shown in Tables 6-8. Mean PPD was always slightly higher for implants in ridge preserved sites at all time points (Table 6). Mean RBL was lower for implants in ridge preserved sites after two and three years in function (Table 7). The percentage of sites with plaque and BOP was always lower for implants in ridge preserved sites at all time points (Table 8).

Although the success rate of implants in ridge preserved sites was slightly less than the success rate of implants placed in ungrafted sites in each year after 2-102 months of function, this difference did not reach statistical significance (Table 9). The overall success rate for all implants in ridge preserved sites was $51 \%$ and for all implants in ungrafted sites was $58 \%$ (Table 5). Apart from ridge preservation, no patient-related parameters (including age, gender, smoking, diabetes) nor implant-related parameters (including system, surface, length, diameter, connection type, surgeon, 1- versus 2-stage surgery, maxilla versus mandible, anterior versus posterior) showed any significant effect on the clinical or radiographic outcomes. 


\section{DISCUSSION}

The aim of the present study was to investigate the survival and success of implants placed after a ridge preservation procedure and to compare them to an ungrafted implant control group. The results of this study revealed similar outcomes.

There is a general lack of homogeneity within the dental literature in regards to reporting the survival and suceess rates of dental implants due to differing criteria between these two terms (Simonis et al. 2010), with many studies reporting solely on survival as the primary outcome and not mentioning success (Lang \& Zitzmann 2012). The survival rate of all implants in this study was $100 \%$. The mean time in function of implants in ridge preserved sites was 31 $( \pm 24)$ months with a range of 2-102 months. Implants placed in ridge preserved sites have also reported high survival rates in the range of $93-100 \%$, but over much shorter observation periods limited to 12 months (Norton \& Wilson 2002, Patel et al. 2013). Survival rates of implants placed in previously ridge preserved sites are similar to those reported for implants placed into sites not requiring any bone augmentation procedures (Albrektsson et al. 1986; Buser et al. 1997; Lindquist et al. 1997; Leonhardt et al. 2002; Bergenblock et al. 2012). Implant placement in compromised sites often requires bone augmentation, whether staged or simultaneous. Following tooth extraction in this study, implants were placed at a range of 43-692 days (mean 268 days) after simultaneous ridge preservation and a range of 109-448 days (mean 266 days) after staged ridge preservation. Particularly in the aesthetic zone, bone augmentation is frequently employed to improve the aesthetic contour, since the buccal plate is often very thin or missing at the anterior maxilla (Farmer and Darby 2014). Donos et al. (2008) reported that irrespective of the ridge augmentation procedure use (GBR, block graft, or split osteotomy), implant survival at augmented sites varied from $91.7 \%$ to $100 \%$ and from $93.2 \%$ to $100 \%$ at the control sites for a period between 12 and 60 months. Jensen \& Terheyden (2009) reported similar implant survival results to Donos et al. (2008) in their literature review, finding that survival rates of implants placed in horizontally (96.9-100\% range) and vertically (95-100\% range) augmented bone were comparable to those of implants in pristine bone over 12-60 months after loading. Although certain factors such as location and timing of implant placement may affect the amount of bone fill obtained from GBR, it appears that overall, the survival and success rates of implants in grafted versus non-grafted sites are comparable (Zitzmann et al. 1999). 
Implant success rates are dependent on the criteria that define their success. Two studies have reported on implant success following ridge preservation in humans. In sockets grafted with bioactive glass, Norton \& Wilson (2002) showed a cumulative success rate of $90 \%$ at one year. Patel et al. (2013) examined success and survival rates of implants in maxillary and mandibular anterior sites placed 8 months after ridge preservation with either an alloplast (Straumann Bone Ceramic ${ }^{\circledR}$ ) or a xenograft (BioOss $\left.®\right)$ ). At 12 months both groups demonstrated $100 \%$ survival and similar success rates ( $84.6 \%$ and $83.3 \%$ respectively), applying success criteria defined by Albrektsson et al. (1986). This study used more recent success criteria as defined by Karoussis et al. (2004) in order to account for the clinical condition of the peri-implant soft tissues (probing pocket depths and bleeding on probing) and hard tissues (radiographic bone levels). This may partly account for the lower overall success rates of $51 \%$ and $58 \%$ for all ridge preserved and ungrafted implant sites respectively, which are lower than in other studies, but similar between the two groups. However, to the authors' knowledge, there are few published studies that have calculated implant success rates using these criteria, which make direct comparisons between studies very difficult. Bazrafshan \& Darby (2014) used these success criteria in their retrospective clinical study and reached the same conclusion, finding that survival and success rates of implants placed in augmented bone from simultaneous GBR procedures were similar to those of implants in pristine bone.

Differences in the mean PPD, BOP, plaque index and radiographic bone loss (RBL) were not statistically significant between implants at ridge preserved or ungrafted sites. However the specific success criteria of one or more implant site with PPD $=5 \mathrm{~mm}$ and BOP was slightly statistically significant $(\mathrm{p}=0.047)$ between the test and control groups, which is similar to Bazrafshan \& Darby (2014). One possible reason for this slight increase in PPD at ridge preserved sites could be the establishment of the first bone-to-implant contact being more apical than the crestal bone level at ungrafted sites, similar to the histological findings reported at immediate implants with regenerated bone by Mellati et al (2015). Clinical assessment of a modified bleeding index in implants placed with simultaneous GBR revealed stable mean values at 1 and 5 years after restoration (Juodzbalys et al. 2007), which is in agreement with our study's stable BOP percentage after 2-7 years in function. The percentage of sites with $\mathrm{BOP}$ and plaque accumulation was always lower for implants in ridge preserved sites than ungrafted sites for all years in function. This may be indicative of adequate oral hygiene practices and compliance with supportive periodontal therapy. Costa 
et al. (2012) reported that individuals with pre-existing peri-implant mucositis present a higher incidence of peri-implantitis over a 5-year period when not enrolled in a maintenance program ( $44 \%$ of patients) compared to those who were ( $18 \%$ of patients).

Mean PPD values were slightly higher at ridge preserved sites for all years in function by approximately $1 \mathrm{~mm}$, but remained relatively stable throughout and within the range of 2$4 \mathrm{~mm}$ for conventionally placed implants under healthy conditions (Lang et al. 2004). No obvious reason for this difference in mean PPD could be determined, although a combination of several factors was proposed. Mombelli \& Lang (1994) suggested that successful implants could allow probe penetration of up to $5 \mathrm{~mm}$, with implants that are placed deeper having deeper probing depths. The emergence profile of the restorative abutments and prostheses may also have an effect on the insertion angle of the periodontal probe. Serino et al. (2013) evaluated the probing depth at implants before and after the removal of the prosthetic reconstructions and reported that only $37 \%$ of sites had similar measurements, with the remainder exhibiting differences of $1 \mathrm{~mm}$ or more. Furthermore, Lang \& Berglundh (2011) emphasised the importance of establishing baseline peri-implant probing records to determine peri-implant hard and soft-tissue changes after physiologic remodelling following installation of the definitive implant prosthesis. In this study baseline PPD values were not available for any implants; therefore we could not discern any increase in PPD over time in function.

The mean RBL values were slightly lower at ridge preserved sites after two and three years in function, but were higher beyond four years in function than the ungrafted sites. Baseline radiographs were not always available, and, when they were available, not necessarily taken with a consistent reproducible technique. Therefore, the mean RBL values recorded in this study could only report on the mesial and distal bone levels at the time of assessment and not as a change from baseline levels. Furthermore, additional crestal bone remodelling beyond the first 12 months after implant placement and functional loading could not be conclusively determined (Zitzmann et al. 2001).

Another outcome reported in the literature on ridge preservation is the dimensional alteration of the alveolar ridge following tooth extraction. Ridge preservation with autogenous bone in a dog model did not enhance or retard healing, nor stimulate hard tissue formation within the socket (Araujo \& Lindhe 2011). Although it failed to prevent resorption of the buccal and palatal bone walls, ridge preservation with a biomaterial (BioOss Collagen $\left.{ }^{\circledR}\right)$ did prevent reduction in the cross sectional area of the alveolar ridge compared to ungrafted controls in 
humans (Araujo et al. 2015). Using the same biomaterial in humans, Cardaropoli et al. (2012) reported that ridge preserved sites maintained $92 \%$ of their original horizontal dimensions at surgical re-entry after 4 months, allowing implant placement without additional grafting at the ridge preserved sites. Despite a substantial minority of implants (19 of 51) in ridge preserved sites requiring additional particulate grafting with either autogenous or xenograft materials in our study, this was recorded as a minor buccal contour augmentation in nature, rather than extensive defect regeneration. Jung et al. (2013) used CBCT imaging to demonstrate a reduced amount of vertical bone loss at the buccal and lingual aspects of alveolar ridges preserved with various biomaterials, six months after tooth extraction. Our study did not specifically measure dimensional changes after ridge preservation; however we can report that all ridge preserved sites were able to have implants successfully placed, with a majority (32 of 51 implants) not requiring additional grafting at time of implant surgery. Importantly, ridge preservation allowed implant placement at sites that were not possible with immediate or delayed surgical protocols. Although there is no conclusive evidence that ridge preservation helped improve the ability to place implants, this outcome serves to dispel questions over the rationale for ridge preservation (Kassim et al. 2014).

Neither patient-related parameters nor implant-related parameters demonstrated any significant effect on the clinical or radiographic outcomes at ridge preserved sites. In the majority of cases, ridge preservation was performed in the anterior maxilla with a flap raised and the use of deproteinised bovine bone mineral (BioOss $\left.{ }^{\circledR}\right)$ and collagen membrane (BioGide $®$ ) materials. This was in agreement with one systematic review's reporting of the most commonly employed ridge preservation technique, which also incorporated flap advancement to achieve complete or partial primary closure (Darby et al. 2009). Our study was not able to discern whether full coverage of the graft material was attained at time of ridge preservation, which may be achieved with coronally repositioned flaps, connective tissue grafts or collagen plugs. A staged ridge preservation procedure 4-6 weeks after tooth extraction can allow for primary soft tissue closure over the socket with keratinised mucosa that makes primary closure more easily attainable. The raising of a mucoperiosteal flap has been associated with increased (Fickl et al. 2008) or decreased (Vignoletti et al. 2012) remodelling of the alveolar ridge, or failed to demonstrate significant differences (Araujo \& Lindhe 2009) between flapped and flapless tooth extractions. In our study, ridge preservation factors such as the adoption of staged or simultaneous procedure, the raising of a mucoperiosteal flap or the type of biomaterials did not make any significant difference to the 
treatment outcome. Overall, our findings concur with conclusions in systematic reviews that there is no evidence that one ridge preservation material or technique is more effective than any other (Darby et al. 2009, Vignoletti et al. 2012).

Intraoral radiographs have been used to analyse interproximal bone levels following various interventions relating to implant therapy (Patel et al. 2013). In this study, a periapical radiograph of each implant was taken using a long-cone paralleling technique with a loop film holder and plain film. Film type, exposure time and processing method were kept consistent to minimise error. Accurate radiographic analysis is also dependent upon the measurement technique. In this study direct measurement of the mesial and distal bone loss from the implant-abutment junction to the first clear bone-to-implant contact on the plain film was recorded (Benic et al. 2009). Wolf et al. (2001) reported that the reproducibility of radiographic measurements was significantly influenced by the examiner. Therefore only one examiner performed all the measurements in this study to minimise bias. Radiographic analysis allows for a simple, non-invasive and reproducible way to monitor interproximal bone loss; however this method of assessment has some limitations. Most significantly, radiographs can only provide a two-dimensional view of a three-dimensional structure, displaying crestal bone levels mesial and distal to each implant without any appreciation of the regenerated bone on the lingual and, in particular, the facial surfaces. The only means available for assessing facial bone alterations at present are via CBCT scanning (Jung et al. 2013) or surgical re-entry (Cardaropoli et al. 2012). It is difficult to justify either option as a routine method of assessment, mainly due to the additional financial cost and radiation exposure of the first option and the biological cost of the second option.

In addition to the clinical and radiographic measurements reported, none of the implants placed in ungrafted sites or ridge preserved sites (either staged or simultaneous) were associated with pain, suppuration, foreign body sensation, mobility or infection at the time of examination.

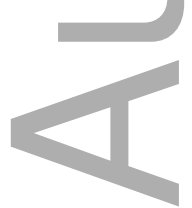

\section{CONCLUSION}

For the patients included in this retrospective study, the data demonstrate that ridge preservation is a predictable procedure, whether performed as a staged procedure or 
simultaneous to tooth extraction. Implants placed at ridge preserved and ungrafted sites demonstrated comparably high survival rates. Implant success rates were similar, if slightly lower, for ridge preserved sites as compared to ungrafted sites.

Conflicts of interest: The authors declare no conflicts of interest.

Acknowledgements: The authors thank the University of Melbourne and Dental Health Services Victoria for their approval to conduct this study.

\section{REFERENCES}

Albrektsson, T., Zarb, G., Worthington, P. \& Eriksson, A.R. (1986) The long-term efficacy of currently used dental implants: a review and proposed criteria of success. International Journal of Oral and Maxillofacial Implants 1:11-25.

Araujo, M. \& Lindhe, J. (2009) Ridge alterations following tooth extraction with and without flap elevation: an experimental study in the dog. Clinical Oral Implants Research 20:545549.

Araujo, M. \& Lindhe, J. (2011) Socket grafting with the use of autologous bone: an experimental study in the dog. Clinical Oral Implants Research 22:9-13.

Araujo, M., da Silva, J., de Mendonca, A. \& Lindhe, J. (2015) Ridge alterations following grafting of fresh extraction sockets in man. A randomized clinical trial. Clinical Oral Implants Research 26:407-412.

Bazrafshan, N. \& Darby, I. (2014) Retrospective success and survival rates of dental implants placed with simultaneous bone augmentation in partially edentulous patients. Clinical Oral Implants Research 25:768-773.

Benic, G., Jung, R.E., Siegenthaler, D.W. \& Hammerle, C.H.F. (2009) Clinical and radiographic comparison of implants in regenerated or native bone: 5-year results. Clinical Oral Implants Research 20:507-513.

Bergenblock, S., Andersson, B., Furst, B. \& Jemt, T. (2012) Long-term follow-up of singleimplant restorations: an 18-year follow-up study based on a prospective patient cohort.

Clinical Implant Dentistry and Related Research 14:471-479. 
Buser, D., Mericske-Stern, R., Bernard, J., Behneke, A., Behneke, N., Belser, D.C. \& Lang, N.P. (1997) Long-term evaluation of non-submerged ITI implants. Part 1: 8-year life table analysis of a prospective multi-center study with 2359 implants. Clinical Oral Implants Research 8:161-172.

Cardaropoli, D., Tamagnome, L., Roffredo, A., Gaveglio, L. \& Cardaropoli, G. (2012) Socket preservation using bovine bone mineral and collagen membrane: a randomized controlled clinical trial with histologic analysis. International Journal of Periodontics Restorative Dentistry 32:421-430.

Chen, S.T. \& Buser, D. (2009) Clinical and esthetic outcomes of implants placed in postextraction sites. International Journal of Oral Maxillofacial Implants 24(Suppl):186-217.

Chen, S.T., Beagle, J., Jensen, S., Chiapasco, M. \& Darby, I. (2009) Consensus Statements and Recommended Clinical Procedures Regarding Surgical Techniques. International Journal of Oral Maxillofacial Implants 24(Suppl.):272-278.

Costa, F.O., Takenaka-Martinez, S., Cota, L.O.M., Ferreira, S.D., Silva, G.L.M. \& Costa, J.E. (2012) Peri-implant disease in subjects with and without preventive maintenance: a 5-year follow-up. Journal of Clinical Periodontology 39:173-181.

Darby, I., Chen, S.T. \& De Poi, R. (2008) Ridge preservation: What is it and when should it be considered? Australian Dental Journal 53:11-21.

Darby, I., Chen, S.T. \& Buser, D. (2009) Ridge preservation techniques for implant therapy. International Journal of Oral Maxillofacial Implants 24:260-271.

Donos, N., Mardas, N. \& Chadha, V. (2008) Clinical outcomes of implants following lateral bone augmentation: systematic assessment of available options (barrier membranes, bone grafts, split osteotomy). Journal of Clinical Periodontology 35(Suppl. 8):173-202.

Farmer, M. \& Darby, I. (2014) Ridge dimensional changes following single-tooth extraction in the aesthetic zone. Clinical Oral Implants Research 25:272-277.

Fickl, S., Zuhr, O., Wachtel, H., Bolz, W. \& Huerzeler, M. (2008) Tissue alterations after tooth extraction with and without surgical trauma: a volumetric study in the beagle dog. Journal of Clinical Periodontology 35:356-363. 
Hämmerle, C.H.F., Chen, S.T. \& Wilson, T.G. (2004) Consensus Statements and Clinical Recommendations Regarding the placement of implants in extraction sockets. International Journal of Oral Maxillofacial Implants 19(Suppl.):26-28.

Jensen, S. \& Terheyden, H. (2009) Bone Augmentation Procedures in Localized Defects in the Alveolar Ridge: Clinical Results with Different Bone Grafts and Bone-Substitute Materials. International Journal of Oral Maxillofacial Implants 24(Suppl):218-236.

Jung, R.E., Philipp, A., Annen, B.M., Signorelli, L., Thoma, D.S., Hammerle, C.H.F., Attin, T. \& Schmidlin, P. (2013) Radiographic evaluation of different techniques for ridge preservation after tooth extraction: a randomized controlled clinical trial. Journal of Clinical Periodontology 40:90-98.

Juodzbalys, G., Raustia, A.M. \& Kubilius, R. (2007) A 5-year follow-up study on one-stage implants inserted concomitantly with localized alveolar ridge augmentation. Journal of Oral Rehabilitation 34:781-789.

Karoussis, I.K., Bragger, U., Salvi, G.E., Burgin, W. \& Lang, N.P. (2004) Effect of implant design on survival and success rates of titanium oral implants: a 10-year prospective cohort study of the ITIs Dental Implant System. Clinical Oral Implants Research 15:8-17.

Kassim, B., Ivanovski, S. \& Mattheos, N. (2014) Current perspectives on the role of ridge (socket) preservation procedure in dental implant treatment in the esthetic zone. Australian Dental Journal 59:48-56.

Lang, N.P., Berglundh, T., Heitz-Mayfield, L.J., Pjetursson, B.E., Salvi, G. \& Sanz, M. (2004) Consensus Statement and recommended clinical procedures regarding implant survival and complications. International Journal of Oral Maxillofacial Implants 19(Suppl.):154-159.

Lang, N.P. \& Berglundh, T. (2011) Peri-implant diseases: where are we now? Consensus of the Seventh European Workshop on Periodontology. Journal of Clinical Periodontology 38(Suppl. 11):178-181.

Lang, N.P. \& Zitzmann, N.U. (2012) Clinical research in implant dentistry: evaluation of implant-supported restorations, aesthetic and patient-reported outcomes. Journal of Clinical Periodontology 39(Suppl 12):133-138. 
Leonhardt, A., Grondahl, K., Bergstrom, C. \& Lekholm, U. (2002) Long-term follow-up of osseointegrated titanium implants using clinical, radiographic and microbiological parameters. Clinical Oral Implants Research 13:127-132.

Lindquist, L.G., Carlsson, G. \& Jemt, T. (1997) Association between marginal bone loss around osseointegrated mandibular implants and smoking habits: a 10 year follow-up study. Journal of Dental Research 76:1667-1674.

Mellati, E., Chen, S.T., \& Darby I. (2015) Healing of Bio-Oss grafted marginal gaps at implants placed into fresh extraction sockets of incisor teeth in dogs: a study on the effect of submerged vs. non-submerged healing. Clinical Oral Implants Research 26:553-562.

Mombelli, A. \& Lang, N. (1994) Clinical parameters for the evaluation of dental implants. Periodontology 2000 4:81-86.

Norton, M.\& Wilson, J. (2002) Dental implant placed in extraction sites implanted with bioactive glass: human histology and clinical outcome. International Journal of Oral Maxillofacial Implants 17:249-257.

Patel, K., Mardas, N. \& Donos, N. (2013) Radiographic and clinical outcomes of implants placed in ridge preserved sites: a 12-month post-loading follow-up. Clinical Oral Implants Research 24:599-605.

Serino, G., Turri, A. \& Lang, N.P. (2013) Probing at implants with peri-implantitis and its relation to clinical peri-implant bone loss. Clinical Oral Implants Research 24(1):91-95.

Simonis, P., Dufour, T. \& Tenenbaum, H. (2010) Long-term implant survival and success: a 10-16-year follow-up of non-submerged dental implants. Clinical Oral Implants Research 21:772-777.

Vignoletti, F., Matesanz, P., Rodrigo, D., Figuero, E., Martin, C. \& Sanz, M. (2012) Surgical protocols for ridge preservation after tooth extraction. A systematic review. Clinical Oral Implants Research 23(Suppl. 5):22-38.

Wolf, B., von Bethlenfalvy, E., Hassfeld, S., Staehle, H.J. \& Eickholz, P. (2001) Reliability of assessing interproximal bone loss by digital radiography: intrabony defects. Journal of Clinical Periodontology 28:869-878. 
Zitzmann, N.U., Scharer, P. \& Marinello, C.P. (1999) Factors influencing the success of GBR. Smoking, timing of implant placement, implant location, bone quality and provisional restoration. Journal of Clinical Periodontology 26:673-682.

Zitzmann, N.U., Scharer, P. \& Marinello, C.P. (2001) Long-term results of implants treated with guided bone regeneration: a 5-year prospective study. International Journal of Oral and Maxillofacial Surgery 16:355-366.

\section{APPENDIX}

Table 1 - Demographic data of subjects, n (\%)

\begin{tabular}{|l|l|l|l|}
\hline & Male & Female & Total \\
\hline Number of patients & $16(38 \%)$ & $26(62 \%)$ & 42 \\
\hline Number of implants & $20(39 \%)$ & $31(61 \%)$ & 51 \\
\hline Mean age \pm SD & & & $53 \pm 16$ \\
\hline Range & & & $24-79$ \\
\hline
\end{tabular}

Table 2 - Distribution of different ridge preservation and flap techniques, and reasons for extraction, $\mathrm{n}(\%)$

\begin{tabular}{|l|l|l|l|}
\hline & Simultaneous RP & Staged RP & Total \\
\hline Number of implants & $27(53 \%)$ & $24(47 \%)$ & 51 \\
\hline Flap technique & & & \\
\hline Flap raised & $15(41 \%)$ & $22(59 \%)$ & 37 \\
\hline Flapless & $12(86 \%)$ & $2(14 \%)$ & 14 \\
\hline Extraction reason & & & \\
\hline vertical root \# & $5(33 \%)$ & $10(67 \%)$ & 15 \\
\hline root \# trauma & $3(50 \%)$ & $3(50 \%)$ & 6 \\
\hline failed RCT & $3(50 \%)$ & $3(50 \%)$ & 6 \\
\hline unrestorable- & $11(79 \%)$ & $3(21 \%)$ & 14 \\
\hline periodontitis & $3(100 \%)$ & $0(0 \%)$ & 3 \\
\hline internal resorption & $1(33 \%)$ & $2(67 \%)$ & 3 \\
\hline other & $1(25 \%)$ & $3(67 \%)$ & 4 \\
\hline
\end{tabular}

Table 3 - Distribution of different graft and membrane materials, n (\%)

\begin{tabular}{|l|l|l|l|l|}
\hline Graft material & Simultaneous RP & Staged RP & Total & \% of total \\
\hline BioOss & $17(41 \%)$ & $24(59 \%)$ & 41 & $80 \%$ \\
\hline
\end{tabular}

This article is protected by copyright. All rights reserved 


\begin{tabular}{|l|l|l|l|l|}
\hline BioOss collagen & $9(100 \%)$ & $0(0 \%)$ & 9 & $18 \%$ \\
\hline 4Bone SBS & $1(100 \%)$ & $0(0 \%)$ & 1 & $2 \%$ \\
\hline Membrane & & & & \\
\hline BioGide & $15(39 \%)$ & $23(61 \%)$ & 38 & $75 \%$ \\
\hline BioMend & $0(0 \%)$ & $1(100 \%)$ & 1 & $2 \%$ \\
\hline BioOss collagen & $1(100 \%)$ & $0(0 \%)$ & 1 & $2 \%$ \\
\hline Spongistan & $4(100 \%)$ & $0(0 \%)$ & 4 & $8 \%$ \\
\hline Collarplug & $2(100 \%)$ & $0(0 \%)$ & 2 & $4 \%$ \\
\hline GelFoam & $2(100 \%)$ & $0(0 \%)$ & 2 & $4 \%$ \\
\hline No membrane & $3(100 \%)$ & $0(0 \%)$ & 3 & $6 \%$ \\
\hline
\end{tabular}

Table 4 - Distribution of implants by system, connection, location, length \& diameter, n (\%)

\begin{tabular}{|c|c|c|c|c|}
\hline Implant System & Simultaneous RP & Staged RP & Ungrafted controls & Total \\
\hline Astra & $15(46 \%)$ & $11(33 \%)$ & $7(21 \%)$ & 33 \\
\hline Biomet 3i & $2(15 \%)$ & $4(31 \%)$ & $7(54 \%)$ & 13 \\
\hline Nobel Biocare & $1(9 \%)$ & $3(27 \%)$ & $7(64 \%)$ & 11 \\
\hline Straumann & $9(25 \%)$ & $6(17 \%)$ & $21(58 \%)$ & 36 \\
\hline \multicolumn{5}{|l|}{ Connection } \\
\hline Internal & $24(30 \%)$ & $20(25 \%)$ & $36(45 \%)$ & 80 \\
\hline External & $3(23 \%)$ & $4(31 \%)$ & $6(46 \%)$ & 13 \\
\hline \multicolumn{5}{|l|}{ Location } \\
\hline Anterior $\mathrm{Mx}$ & $17(41 \%)$ & $15(37 \%)$ & $9(22 \%)$ & 41 \\
\hline Posterior Mx & $7(27 \%)$ & $6(23 \%)$ & $13(50 \%)$ & 26 \\
\hline Anterior Md & $0(0 \%)$ & $1(33 \%)$ & $2(67 \%)$ & 3 \\
\hline Posterior Md & $3(13 \%)$ & $2(9 \%)$ & $18(78 \%)$ & 23 \\
\hline \multicolumn{5}{|l|}{ Length $(\mathrm{mm})$} \\
\hline$\leq 8.0$ & $6(35 \%)$ & $2(12 \%)$ & $9(53 \%)$ & 17 \\
\hline $8.1-11.9$ & $19(29 \%)$ & $20(30 \%)$ & $27(41 \%)$ & 66 \\
\hline$\geq 12.0$ & $2(20 \%)$ & $2(20 \%)$ & $6(60 \%)$ & 10 \\
\hline \multicolumn{5}{|l|}{ Diameter (mm) } \\
\hline$<3.75$ & $2(12 \%)$ & $5(29 \%)$ & $10(59 \%)$ & 17 \\
\hline $3.75-4.4$ & $21(34 \%)$ & $18(29 \%)$ & $23(37 \%)$ & 62 \\
\hline$\geq 4.5$ & $4(29 \%)$ & $1(7 \%)$ & $9(64 \%)$ & 14 \\
\hline
\end{tabular}

Table 5 - Success data by ridge preservation type, $\mathrm{n}(\%)$

This article is protected by copyright. All rights reserved 


\begin{tabular}{|l|l|l|l|}
\hline Success criteria & All RP & Ungrafted controls & P value \\
\hline No site with PPD $>5 \mathrm{~mm}$ & $43(84 \%)$ & $40(95 \%)$ & 0.09 \\
\hline No site with PPD $=5 \mathrm{~mm}+$ BOP & $38(75 \%)$ & $38(90 \%)$ & 0.047 \\
\hline No site with BOP +ve & $4(8 \%)$ & $5(12 \%)$ & 0.5 \\
\hline No site with RBL >1mm & $43(84 \%)$ & $29(69 \%)$ & 0.08 \\
\hline No RBL $\geq 0.2 \mathrm{~mm} / \mathrm{yr}$ & $39(76 \%)$ & $28(67 \%)$ & 0.4 \\
\hline Overall success & $26(51 \%)$ & $24(58 \%)$ & 0.5 \\
\hline
\end{tabular}

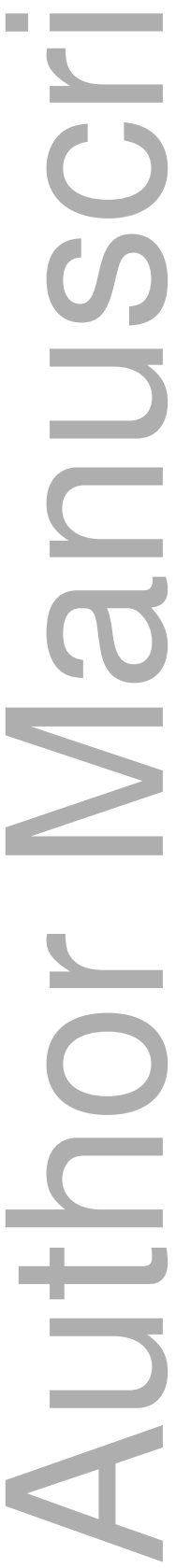

This article is protected by copyright. All rights reserved 
Table 6 - Mean PPD by years in function, $\mathrm{mm}$

\begin{tabular}{|l|l|l|l|l|l|l|l|l|l|l|l|l|}
\hline \multicolumn{9}{|l|}{ All RP } & \multicolumn{9}{l|}{ Ungrafted controls } \\
\hline Years in function & Implants & Mean (mm) & $\mathbf{\pm}$ SD & Median & Range & $\mathbf{9 5 \%}$ CI & Implants & Mean $(\mathbf{m m})$ & \pm SD & Median & Range & $\mathbf{9 5 \%}$ CI \\
\hline$\leq 2$ & 51 & 3.45 & 0.80 & 3.17 & $1.67-5.83$ & $3.23-3.67$ & 42 & 2.48 & 0.63 & 2.25 & $1.50-4.00$ & $2.29-2.67$ \\
\hline 3 & 31 & 3.74 & 0.78 & 3.83 & $2.67-5.83$ & $3.46-4.02$ & 39 & 2.47 & 0.64 & 2.17 & $1.50-4.00$ & $2.27-2.67$ \\
\hline 4 & 25 & 3.74 & 0.80 & 3.83 & $2.67-5.83$ & $3.43-4.05$ & 33 & 2.53 & 0.64 & 2.17 & $1.50-4.00$ & $2.31-2.75$ \\
\hline 5 & 16 & 3.72 & 0.93 & 3.58 & $2.67-5.83$ & $3.26-4.18$ & 28 & 2.61 & 0.66 & 2.50 & $1.50-4.00$ & $2.37-2.85$ \\
\hline 6 & 11 & 3.62 & 0.79 & 3.33 & $2.67-5.17$ & $3.15-4.09$ & 18 & 2.61 & 0.57 & 2.50 & $2.00-4.00$ & $2.35-2.87$ \\
\hline$\geq 7$ & 6 & 3.75 & 0.92 & 3.25 & $3.00-5.17$ & $3.01-4.49$ & 8 & 2.48 & 0.68 & 2.17 & $2.00-4.00$ & $2.01-2.95$ \\
\hline
\end{tabular}

Table 7 - Mean RBL by years in function, $\mathrm{mm}$

\begin{tabular}{|l|l|l|l|l|l|l|l|l|l|l|l|l|l|}
\hline \multicolumn{10}{|l|}{ Ull RP } & \multicolumn{10}{l|}{ Ungrafted controls } \\
\hline Years in function & Implants & Mean $(\mathbf{m m})$ & $\mathbf{\pm}$ SD & Median & Range & $\mathbf{9 5 \%}$ CI & Implants & Mean $(\mathbf{m m})$ & \pm SD & Median & Range & $\mathbf{9 5 \%}$ CI \\
\hline$\leq 2$ & 51 & 0.44 & 0.67 & 0.00 & $0.00-2.50$ & $0.26-0.62$ & 42 & 0.75 & 1.03 & 0.11 & $0.00-4.00$ & $0.44-1.06$ \\
\hline 3 & 31 & 0.66 & 0.78 & 0.25 & $0.00-2.50$ & $0.39-0.93$ & 39 & 0.73 & 1.00 & 0.21 & $0.00-4.00$ & $0.42-1.04$ \\
\hline 4 & 25 & 0.80 & 0.80 & 0.75 & $0.00-2.50$ & $0.48-1.12$ & 33 & 0.63 & 0.88 & 0.00 & $0.00-3.15$ & $0.33-0.93$ \\
\hline 5 & 16 & 0.83 & 0.83 & 0.75 & $0.00-2.50$ & $0.42-1.24$ & 28 & 0.68 & 0.93 & 0.11 & $0.00-3.15$ & $0.34-1.02$ \\
\hline 6 & 11 & 1.09 & 0.87 & 1.00 & $0.00-2.50$ & $0.58-1.60$ & 18 & 0.76 & 1.02 & 0.11 & $0.00-3.15$ & $0.29-1.23$ \\
\hline$\geq 7$ & 6 & 1.50 & 0.89 & 1.75 & $0.00-2.50$ & $0.78-2.22$ & 8 & 0.56 & 0.79 & 0.11 & $0.00-2.00$ & $0.01-1.11$ \\
\hline
\end{tabular}

This article is protected by copyright. All rights reserved 
Table 8 - Percentage of sites with Plaque and BOP by years in function

\begin{tabular}{|l|l|l|l|l|l|l|l|l|l|l|}
\hline & \multicolumn{9}{|l|}{ Plaque (\% \pm SD) } & \multicolumn{3}{l|}{ BOP $(\% \pm$ SD) } \\
\hline Years in function & RP Implants & Control implants & All RP (\%) & \pm SD & Controls & \pm SD & All RP(\%) & \pm SD & Controls & \pm SD \\
\hline$\leq 2$ & 51 & 42 & 27 & 25 & 44 & 34 & 49 & 28 & 59 & 37 \\
\hline 3 & 31 & 39 & 29 & 26 & 45 & 35 & 55 & 30 & 59 & 38 \\
\hline 4 & 25 & 33 & 29 & 29 & 44 & 36 & 57 & 32 & 60 & 38 \\
\hline 5 & 16 & 28 & 27 & 24 & 50 & 35 & 52 & 26 & 69 & 33 \\
\hline 6 & 11 & 18 & 24 & 22 & 53 & 38 & 42 & 22 & 66 & 37 \\
\hline$\geq 7$ & 6 & 8 & 25 & 23 & 33 & 43 & 39 & 17 & 54 & 46 \\
\hline
\end{tabular}

Table 9 -Percentage of successful implants by years in function, and ridge preservation versus ungrafted controls

\begin{tabular}{|l|l|l|l|l|l|}
\hline Years in function & RP implants & RP success (\%) & Control implants & Control success (\%) & Overall success (\%) \\
\hline$\leq 2$ & 51 & 51 & 42 & 58 & 54 \\
\hline 3 & 31 & 42 & 39 & 56 & 50 \\
\hline 4 & 25 & 40 & 33 & 61 & 52 \\
\hline 5 & 16 & 44 & 28 & 61 & 55 \\
\hline 6 & 11 & 46 & 18 & 61 & 55 \\
\hline$\geq 7$ & 6 & 33 & 8 & 44 & 39 \\
\hline
\end{tabular}

This article is protected by copyright. All rights reserved 


\section{University Library}

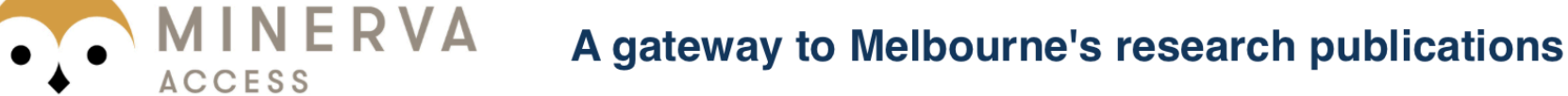

Minerva Access is the Institutional Repository of The University of Melbourne

Author/s:

Apostolopoulos, P;Darby, I

Title:

Retrospective success and survival rates of dental implants placed after a ridge preservation procedure.

Date:

2017-04

Citation:

Apostolopoulos, P. \& Darby, I. (2017). Retrospective success and survival rates of dental implants placed after a ridge preservation procedure.. Clin Oral Implants Res, 28 (4), pp.461-468. https://doi.org/10.1111/clr.12820.

Persistent Link:

http://hdl.handle.net/11343/291021 